\title{
Implementasi Pemenuhan Hak Pendidikan Warga Negara Indonesia Di Perbatasan Darat Antara Indonesia Dan Malaysia
}

\author{
Endah Rantau Itasari ${ }^{1 *}$ \\ ${ }^{1}$ Fakultas Hukum, Universitas Tanjungpura,Pontianak, Indonesia
}

\section{A R T I C L E I N F O}

Article history:

Received 31 Oktober 2018

Accepted 30 November 2018

Available online 31

Desember 2018

\section{Kata Kunci:}

Hak atas pendidikan;

Perbatasan darat;

Indonesia; Malaysia

Keywords:

The right to education;

Land border; Indonesia;

Malaysia

pendidikan dasar dan menengah..

\section{A B S T R A C T}

The implementation of the right to education derived from the Constitution of the Republic of Indonesia in 1945 and the basic provisions of international human rights law as in the 1949 Universal Declaration on Human Rights (UDHR), The International Covenant on Economic, Social and Cultural Rights (ICESCR) 1966 and in The Convention on the Rights of the Child 1989. The nature of the right to education at the primary education level, as stated in the ICESCR, is a certain condition must be created by the ratifying state. The aspect of the substance of education and managerial education implementation is a basic element in Article 13 of the ICESCR for the state to provide basic education for everyone. Aspects of availability and ease of education facilities and infrastructure, and aspects of acceptance and adaptability are legal segments (indicators) which must be conditioned gradually by the state to be achieved at any time and to be fulfilled in the field of education, especially primary and secondary education.

\footnotetext{
* Corresponding author.

E-mail addresses: itafira@yahoo.com
} 


\section{Pendahuluan}

Eksistensi hak atas pendidikan sudah tidak diragukan lagi keberadaannya baik di tingkat nasional maupun internasional (Dieter;2005;1). Khusus di Indonesia, dinamika politik hukum nasional mempengaruhi pelaksanaan hak atas pendidikan yang berasal dari Undang-Undang Dasar Negara Republik Indonesia Tahun 1945 (UUD 1945) dan ketentuan-ketentuan pokok hukum hak asasi manusia internasional seperti dalam The Universal Declaration on Human Rights (UDHR)1949, The International Covenant on Economic, Social and Cultural Rights (ICESCR)1966 dan dalam The Convention on The Rights of The Child 1989.

Dalam Pembukaan UUD 1945 ditegaskan bahwa salah satu tujuan dibentuknya pemerintahan Negara Indonesia adalah "untuk mencerdaskan kehidupan bangsa". Tujuan ini kemudian dimanifestasikan melalui Pasal 28C ayat (1) dan Pasal 31 UUD 1945 dan dijabarkan lebih lanjut dalam berbagai peraturan perundang-undangan termasuk Undang-Undang No. 20 Tahun 2003 tentang Sistem Pendidikan Nasional sebagai lex specialis. Berkaitan dengan ICESCR, Indonesia telah meratifikasi kovenan tersebut pada tanggal 30 September 2005 melalui UndangUndang Nomor 11 Tahun 2005 tentang Pengesahan theInternational Covenant on Economic, Social and Cultural Rights (Kovenan Internasional tentang Hak-Hak Ekonomi, Sosial dan Budaya yang termuat dalam Lembaran Negara Republik Indonesia Tahun 2005 Nomor 118). Dalam ICESCR sendiri hak atas pendidikan khususnya diatur dalam Pasal 13 dan Pasal 14.

Hakekat hak atas pendidikan pada tingkat pendidikan dasar, sebagaimana ditegaskan dalam ICESCR, merupakan suatu kondisi tertentu harus diciptakan oleh negara peratifikasi (Freeman; 1992; 1). Aspek substansi pendidikan dan manajerial penyelenggaraan pendidikan merupakan elemen dasar dalam Pasal 13 ICESCR bagi negara untuk menyediakan pendidikan dasar bagi setiap orang. Aspek ketersediaan dan kemudahan sarana dan prasarana pendidikan, dan aspek penerimaan dan daya penyesuaian merupakan segmen-segmen hukum (indikator) yang harus dikondisikan pemenuhannya secara bertahap oleh negara untuk setiap saat dicapai dan ditingkatkan pemenuhannya dalam bidang pendidikan, khususnya pendidikan dasar dan menengah (Katarina;1995;1).

Indonesia sebagai pihak pada ICESCR terikat untuk melaksanakan ketentuan-ketentuan tersebut berdasarkan kewajiban-kewajian internasional yang terkandung didalamnya (Santos ;5). Bonanza Perwira Taihitu memberikan kerangka argumentatif bahwa politik hukum nasional Indonesia terhadap pelaksanaan ketentuan-ketentuan hukum hak asasi manusia internasional tersebut di atas antara tahun 1990 sampai dengan akhir tahun 2005 lebih cenderung bersifat sebagai sebuah pencitraan nasional di forum internasional (Bonanza;2003;143). Dengan demikian, kewajiban-kewajiban dasar dalam ketentuan tersebut dilaksanakan untuk lebih menarik simpati luar negeri dari pada pemanfaatannya untuk kepentingan nasional.

Provinsi Kalimantan Barat (Kalbar) telah dijadikan telaah kajian dan inisiasi peningkatan pemenuhan hak atas pendidikan oleh Kemdikbud sejak tahun 2009 khususnya di wilayah perbatasan dengan Malaysia. Minimnya sarana dan prasarana, rendahnya keinginan bersekolah, keengganan pelaku pendidikan melaksanakan tugas dan fungsi pendidik dan rendahnya alokasi dana pendidikan telah menyebabkan ketertinggalan dan ketimpangan memperoleh akses pendidikan di wilayah-wilayah perbatasan tersebut (Marzuki; 2011).

Sebagian besar wilayah perbatasan Kalimantan Barat dengan Sarawak, Malaysia juga termasuk sebagai Daerah Tertinggal, Terdepan dan Terluar (D3T) yang saat ini menjadi prioritas pembangunan sesuai dengan visi Nawacita dari Presiden Joko Widodo. Pada tahun 2015, telah ditetapkan 122 kabupaten sebagai daerah tertinggal dan 43 daerah terdepan dan terluar berdasarkan Surat No. 2421/Dt.7.2/04/2015 tanggal 21 April 2015 oleh Kementerian Perencanaan Pembangunan Nasional/Badan Perencanaan Pembangunan Nasional (Kemen PPN/BAPPENAS). Dalam daftar tersebut Kabupaten Sambas, Kabupaten Bengkayang, Kabupaten Sintang dan Kabupaten Kapuas Hulu termasuk dalam D3T.

Untuk mengatasi pemenuhan hak pendidikan di wilayah D3T ini, berbagai kebijakan sebenarnya telah dilakukan oleh pemerintah, salah satunya adalah dengan program Sarjana Mengajar di Daerah Terdepan, Terluar dan Tertinggal (SM-3T) untuk mengatasi kekurangan pengajar di daerah perbatasan. Gerakan SM-3T merupakan solusi dari permasalahan kurangnya tenaga pendidik di D3T. Dari gerakan tersebut para lulusan S1 kependidikan dapat mentransfer 
ilmunya kepada orang-orang yang memang benar-benar membutuhkan. Dalam gerakan tersebut para pendidik dikirim ke daerah D3T yang ada di luar pulau jawa terutama di bagian timur Indonesia seperti pedalaman Kalimantan, Sulawesi, Papua dan lain sebagainya.

Manfaat dari hadirnya gerakan tersebut selain untuk membantu kurangnya tenaga pendidik di D3T juga untuk mempersiapkan tenaga pendidik yang tangguh, mandiri dan berkompetensi serta memiliki pengetahuan yang luas mengenai kondisi pendidikan di Indonesia sehingga dengan secara sadar calon pendidik tersebut dapat memanfaatkan ilmunya dengan baik untuk membangun dan mencerdaskan bangsa. Selain itu dengan adanya gerakan tersebut juga bermanfaat untuk menciptakan tenaga pendidik yang memiliki jiwa sosial yang tinggi karena dengan pengalaman mengikuti gerakan tersebut calon pendidik ikut merasakan kehidupan orang-orang di D3T sehingga tergerak jiwanya untuk dapat memperbaiki kehidupan mereka melalui jalur pendidikan.

Pemerintah masih belum serius menangani masalah akses pendidikan di Kalimantan Barat, Kalimantan Barat merupakan provinsi yang sebagian besar terdiri atas perairan. Maka akses antar daerah di Kalimantan Barat sebagian besar menggunakan transportasi sungai. Oleh karena itu, pemerintah harus dapat memaksimalkan transportasi yang ada di Kalimantan Barat seperti jembatan, dermaga, serta sarana prasarana pendukung lainnya. Intinya pemerintah harus memberikan perhatian khusus bagi lembaga pendidikan yang berdomisili di daerah yang memiliki keterbatasan akses pendidikan. Solusi yang terbaik adalah perluasan akses pendidikan serta pemerataan layanan pendidikan baik di daerah terpencil maupun di daerah perkotaan.

\section{Metode}

Berdasarkan sifatnya, penelitian ini adalah penelitian yang bersifat deskriptif yaitu penelitian yang bermaksud untuk memberikan data yang seteliti mungkin mengenai Implementasi Pemenuhan Hak Pendidikan Warga Negara Indonesia di Perbatasan Darat antara Indonesia dan Malaysia, penelitian ini adalah penelitian evaluatif dan preskriptif, tujuan penelitian hukum ini adalah penelitian hukum normatif dan kepustakaan.

\section{Hasil dan pembahasan}

Dalam tataran normatif, untuk memastikan pemenuhan kebutuhan masyarakat akan pendidikan yang layak, negara mempunyai kewajiban untuk memastikan penyediaan sistem pendidikan dan kurikulum yang memadai, penyediaan beasiswa, penyediaan sarana dan prasarana yang memadai, meningkatkan kualitas tenaga pendidik baik guru maupun dosen di perguruan tinggi (Committee on Economic, Social and Cultural Rights General Comment 13;2002). Menurut kewajiban yang terkandung dalam ICESCR, sistem pendidikan yang ditetapkan oleh pemerintah harus dapat menjangkau semua warganegara, dapat diakses secara bebas tanpa diskriminasi dan secara ekonomi dan psikologis dapat diterima, serta sifatnya dapat menyesuaikan diri dengan perkembangan zaman (Wringe, 2006;51).

Putusan Mahkamah Konstitusi dalam Perkara Nomor 012/PUU-III/2005 Mengenai Pengujian UU No. 36 Tahun 2004 Tentang APBN terhadap pengakuan, pemajuan dan perlindungan hak asasi manusia dalam bidang pendidikan mempertegas perdebatan lama yang tidak kunjung akhir mengenai kewajiban negara terhadap pemenuhan hak ekonomi, sosial dan budaya seperti yang termaktub dalam Konvenan (Jaka; Vol. 4 Nomor 1, Juni 2006). Persoalanpersoalan seperti akses terhadap pendidikan, pengurangan siswa putus sekolah, penguatan dan dukungan atas institusi-institusi pendidikan dasar umum dan khusus yang sudah ada dan penanganan akses pendidikan di wilayah terpencil belum tertanggulangi secara nyata.

Mutu pendidikan di Kalimantan Barat masih terbilang rendah. Hal tersebut terbukti dengan out put (keluaran) yang di produksi di Kalimantan Barat belum menunjukkan tingkat keberhasilan pendidikan. Kalimantan Barat setiap tahunnya mengeluarkan ribuan sarjana baru, namun belum memberikan dampak peningkatan mutu pendidikan di Indonesia. Selain itu, Kalimantan Barat belum bisa bersaing secara maksimal baik itu di tingkat nasional maupun internasional. Solusi yang terbaik adalah pemerintah harus selalu berupaya untuk meningkatkan mutu pendidikan dan daya saing lulusan yang ada di Kalimantan Barat. 
Tabel 1. Menurut Pendidikan Tertinggi yang Ditamatkan, Februari 2013-2015

\begin{tabular}{llll}
\hline \multirow{2}{*}{ Pendidikan Tertinggi yang Ditamatkan } & 2013 & 2014 & 2015 \\
\cline { 2 - 4 } & Februari & Februari & Februari \\
(1) & $(2)$ & $(3)$ & $(4)$ \\
SD Ke Bawah & 1.364 & 1.352 & 1.189 \\
Sekolah Menengah Pertama & 354 & 364 & 375 \\
Sekolah Menengah Atas & 306 & 320 & 375 \\
Sekolah Menengah Kejuruan & 97 & 102 & 140 \\
Diploma I/II/III & 52 & 70 & 58 \\
Universitas & 103 & 101 & 121 \\
\hline Jumlah & & & \\
\hline
\end{tabular}

Sumber : BPS Provinsi Kalimantan Barat, 2015.

Berdasarkan tabel di atas menyatakan bahwa di Kalimantan Barat pendidikan tertinggi yang ditamatkan melalui data bulan Februari tahun 2013 sampai 2015 menunjukan hal yang positif. Akan tetapi dengan hasil seperti tersebut pendidikan di Kalimantan Barat masih menyimpan permasalahan yang segera dicarikan jalan keluarnya.

Pemerintah masih belum maksimal dalam mengelola pendidikan di Kalimantan Barat. Salah satu bukti kuat yang mendukung pernyataan penulis tersebut adalah belum seriusnya pemerintah dalam menyimbangkan pendidikan umum dengan pendidikan keagamaan. Baik itu dalam hal sarana dan prasarana maupun dalam hal financial. Solusi yang terbaik adalah pemerintah harus dapat mengelola pendidikan secara maksimal agar hasil yang didapatkan juga maksimal. Caranya adalah dengan meniadakan diskriminatif antara pendidikan umum dengan pendidikan keagamaan. Pemerataan beasiswa bagi peserta didik, pemerataan sarana dan prasarana penunjang pendidikan serta pengawasan yang intensif terhadap penyaluran dan penggunaan dana, apakah tepat sasaran atau disalahgunakan.

Selain ketiga permasalahan diatas, penulis masih merasa janggal dengan pengelolaan tenaga pendidik di Kalimantan Barat. Hal itu terbukti dengan pemerataan tenaga pendidik yang belum maksimal. Pendidikan di Provinsi Kalimantan Barat masih jauh tertinggal dibandingkan dengan provinsi lainnya di Indonesia. Hal itu salah satunya disebabkan oleh tidak memadainya jumlah tenaga pendidik di Kalimantan Barat. Kalimantan Barat masih memerlukan banyak tenaga pendidik, agar jumlah tenaga pendidik tersebut seimbang dengan jumlah lembaga pendidikan, jumlah penduduk serta luas wilayah Kalimantan Barat.

Selain itu, dinamika politik lokal dengan dilaksanakannya kebijakan desentralisasi yang berupa pelimpahan kewenangan penyelenggaraan pendidikan dari Pemerintah Pusat ke Pemda sebagai jawaban pemerataan dan efektivitas pelaksanaan pendidikan juga tidak dengan sendirinya membuat pemenuhan hak atas pendidikan dasar dan menegah di wilayah perbatasan Malaysia di Kalbar dapat dipenuhi secara minimal. Sebaliknya, pelimpahan kewenangan ini justru berakibat pada pemunduran kualitas pendidikan sebab tidak semua pemerintahan daerah kabupaten memiliki kemampuan yang sama, baik dari sisi kapasitas personel dan anggaran yang merata. Akibatnya disparitas antar kabupaten menjadi kelihatan nyata dan menjadi pemandangan sehari-hari. Lebih khusus lagi, banyak sekali laporan tentang robohnya gedung sekolah dan fasilitas sekolah yang jauh dari kebutuhan menunjang proses belajar mengajar, termasuk juga minimnya jumlah guru tetap yang mesti dimiliki oleh setiap institusi pendidikan. 
Pada tataran legislasi, meskipun telah ada Undang-Undang 20 Tahun 2003 tentang Sistem Pendidikan Nasional (UU Sisdiknas), pada level daerah baik Provinsi maupun Kabupaten/Kota di Kalimantan Barat belum terdapat peraturan daerah yang mengatur khusus mengenai masalah pendidikan. Hal ini merupakan konsekuensi dari undang-undang Pemerintahan Daerah yang menegaskan bahwa urusan pendidikan masih merupakan urusan pemerintah pusat. Dengan demikian daerah tidak mengatur hal tersebut lebih lanjut pada tataran legislasi daerah.

Dengan kebijakan pemerintahan saat ini yang ingin memulai pembangunan dari wilayah perbatasan dan wilayah terluar semestinya kondisi pemenuhan hak atas pendidikan bagi masyarakat di wilayah perbatasan menjadi salah satu prioritas. Dengan demikian diperlukan sebuah kajian untuk mendapatkan gambaran mengenai politik hukum dan kebijakan negara dalam memenuhi hak atas pendidikan dasar dan menengah bagi masyarakat di perbatasan Kalimantan Barat dengan Sarawak. Analisis situasi dan kebutuhan terhadap pemenuhan hak atas pendidikan dasar dan menengah di wilayah perbatasan negara di Provinsi Kalbar perlu dilakukan secara menyeluruh terhadap kebijakan, program, kegiatan dan pendanaan dalam pemenuhan hak atas pendidikan.

Pelaksanaan indikator-indikator tersebut akan menghasilkan akuntabilitas dan legitimasi yang dapat diterima khususnya dalam implementasi instrumen-instrumen hukum internasional yang telah diratifikasi Indonesia. Secara teoritis praktis, indikator legal pelaksanaan tersebut di atas dapat diukur melalui sistematisasi pada budaya hukum (legal culture); struktur hukum (legal structure) dan substansi hukum (legal substance) terhadap upaya pemenuhan hak atas pendidikan. Daya paksa berlakunya hukum akan memperoleh justifikasi legal, sosial dan politik sehingga pemberlakuan ini dapat digunakan sebagai referensi bagi pemenuhan hak atas pendidikan dasar dan menengah di wilayah perbatasan negara yang lainnya yaitu di Papua dan di NTT.

\section{Simpulan dan saran}

Pelaksanaan pemenuhan hak atas pendidikan dasar dan menengah di kawasan perbatasan Provinsi Kalimantan Barat sejak tahun 2005 sampai 2007 telah secara bertahap dipenuhi oleh pemerintah. Pemenuhan secara bertahap tersebut merupakan pelaksanaan kedaulatan negara sebagai bentuk tanggung jawab untuk menghormati pelaksanaan agenda global dalam pemenuhan hak atas pendidikan yang telah digunakan untuk mengontestasi agenda tersebut dalam pembuatan hukum, kebijakan, program dan pendanaan. Sayangnya, pelaksanaan pemenuhan hak atas pendidikan dasar dan menengah di kawasan perbatasan Indonesia dan Malaysia di Provinsi Kalimantan Barat memiliki permasalahan, kendala sekaligus tantangan khusus. Semua disebabkan karena situasi dan kondisi tertentu yang ada di wilayah perbatasan. Terkait situasi dan kondisi ini, terdapat 11 klaster temuan permasalahan pemenuhan hak atas pendidikan oleh Kementerian Pendidikan dan Kebudayaan RI. Salah satu klaster permasalahan adalah munculnya wilayah-wilayah tak berkeinginan sekolah pada tingkat dasar dan menengah di kawasan perbatasan negara di Provinsi Kalimantan Barat, khususnya di wilayah Sambas, Bengkayang, Sanggau, Sintang dan Kabupaten Kapuas Hulu, dalam tataran normatif untuk memastikan pemenuhan kebutuhan masyarakat akan pendidikan yang layak, negara memiliki kewajiban memastikan penyediaan sistem pendidikan dan kurikulum yang memadai. Selain itu, juga penyediaan beasiswa, sarana dan prasarana, meningkatkan kualitas mutu tenaga pendidik guru maupun dosen. Kewajiban-kewajiban yang terkandung dalam ICESCR, sistem pendidikan yang ditetapkan pemerintah harus menjangkau semua warga negara sehingga semua itu dapat diakses secara bebas tanpa diskriminasi dan secara ekonomi dan psikologis dapat diterima, serta sifatnya yang dapat menyesuaikan diri dengan perkembangan zaman.

\section{Daftar Rujukan}

Beiter, Klaus Dieter. 2005. The Protection of the Right to Education by International Law. Martinus Nijhoff Publisher. 
Committee on Economic, Social and Cultural Rights General Comment 13, The Right to Education (Art. 13), 08/12/99, E/C.12/1999/10, CESCR, 8 December 1999, para 1; pernyataan ini didukung oleh the World Bank in Crying Out for Change, World Bank in three volumes (2002).

Freeman, M. 1992. The Limits of Children's Rights. dalam The Ideologies of Children's Rights.

Kovenan Internasional tentang Hak-Hak Ekonomi, Sosial dan Budaya yang termuat dalam Lembaran Negara Republik Indonesia Tahun 2005 Nomor 118, Tambahan Lembaran Negara Republik Indonesia Nomor 4557.

Marzuki. 2011. Permasalahan Pemenuhan Hak Atas Pendidikan di Wilayah Provinsi Kalimantan Barat. Makalah Forum Grup Discussion, Pemetaan Permasalahan Pendidikan Di Wilayah Perbatasan Negara, Setjen Kemdikbud, Hotel Park Jakarta, 23-24 November 2011.

Perwira Taihitu, Bonanza. 2003. Penaatan Indonesia Pada Standar-Standar Hak Asasi Manusia Internasional. Thesis Fisipol, Universitas Indonesia, 2003.

Santos Pais, M. A Human Rights Conceptual Framework for Children's Rights. dalam UNICEF Innovative Essay, 9.

Tomasevski, Katarina. 1995. Indicators. dalam Asbjorn Eide (et.all). Economic, Social and Cultural Rights A Textbook.

Triyana, Heribertus Jaka. 2006. Implikasi Hukum Ratifikasi Kovenan Hak Ekonomi Sosial dan Budaya Terhadap Pemenuhan Hak Atas Pendidikan di Indonesia. Jurnal Hukum dan HAM, 4(1).

Wringe, Colin. 2006. Moral Education: Beyond the Teaching Rights and Wrong. Springer. 